University of Nebraska - Lincoln

DigitalCommons@University of Nebraska - Lincoln

Agronomy \& Horticulture -- Faculty Publications

Agronomy and Horticulture Department

2007

\title{
Simulation study of the competitive ability of erect, semi-erect, and prostrate cowpea (Vigna unguiculata) genotypes
}

\author{
G. Wang \\ University of California, Riverside \\ M. E. McGiffen Jr. \\ University of California, Riverside \\ John L. Lindquist \\ University of Nebraska-Lincoln, jlindquist1@unl.edu \\ J. D. Ehlers \\ University of California, Riverside \\ I. Sartorato \\ Istituto di Biologia Agroambientale e Forestale del CNR, Legnaro, Padova, Italy
}

Follow this and additional works at: https://digitalcommons.unl.edu/agronomyfacpub

Part of the Plant Sciences Commons

Wang, G.; McGiffen, M. E. Jr.; Lindquist, John L.; Ehlers, J. D.; and Sartorato, I., "Simulation study of the competitive ability of erect, semi-erect, and prostrate cowpea (Vigna unguiculata) genotypes" (2007). Agronomy \& Horticulture -- Faculty Publications. 402.

https://digitalcommons.unl.edu/agronomyfacpub/402

This Article is brought to you for free and open access by the Agronomy and Horticulture Department at DigitalCommons@University of Nebraska - Lincoln. It has been accepted for inclusion in Agronomy \& Horticulture -Faculty Publications by an authorized administrator of DigitalCommons@University of Nebraska - Lincoln. 
Published in Weed Research 47:2 (2007), pp. 129-139; doi: 10.1111/j.1365-3180.2007.00550.x

Copyright ( 12007 G. Wang, M. E. McGiffen Jr., J. L. Lindquist, J. D. Ehlers, \& I. Sartorato.

Published by European Weed Research Society and Wiley-Blackwell. Used by permission.

\title{
Simulation study of the competitive ability of erect, semi-erect, and prostrate cowpea (Vigna unguiculata) genotypes
}

\author{
G. Wang, ${ }^{1}$ M. E. McGiffen Jr., ${ }^{1}$ J. L. Lindquist, ${ }^{2}$ J. D. Ehlers, ${ }^{1}$ and I. Sartorato ${ }^{3}$ \\ 1. Department of Botany and Plant Sciences, University of California, Riverside, CA, USA \\ 2. Department of Agronomy and Horticulture, University of Nebraska, Lincoln, NE, USA \\ 3. Istituto di Biologia Agroambientale e Forestale del CNR, Legnaro, Padova, Italy \\ Corresponding author - M. E. McGiffen Jr., Department of Botany and Plant Sciences, University of California, \\ Riverside, CA, 92521-0124, USA; tel 909 560-0839, fax 951 827-5717, email milt@ucr.edu
}

\begin{abstract}
Ecophysiological simulation models provide a quantitative method to predict the effects of management practices, plant characteristics, and environmental factors on crop and weed growth and competition. The INTERCOM interplant competition model was parameterized, calibrated by monoculture data for three cowpea (Vigna unguiculata) genotypes that differed in growth habit, common sunflower (Helianthus annuus) and common purslane (Portulaca oleracea), and used to simulate competition of cowpea cover crops with sunflower or purslane. The simulation results were compared with observations from field competition experiments in 2003 and 2004. INTERCOM more accurately simulated actual field data for the competition of cowpea genotypes and sunflower than companion field experiments for the competition of cowpea and purslane. The validated simulation model of cowpea and sunflower at two densities was used to study the effects of cowpea growth habit on final biomass production of cowpea and sunflower. The model suggested that erect growth habit was more competitive than semi-erect and prostrate growth habit, when cowpea genotypes were grown with sunflower. Cowpea leaf area distribution was important to higher cowpea biomass production, while cowpea height growth was important to reduce sunflower biomass. Our simulation approach is suggested as a method for crop breeders to gauge the likely success of selection for competitive crops before undertaking expensive long-term breeding experiments.
\end{abstract}

Keywords: cover crop, growth habit, interplant competition, INTERCOM model, Helianthus annuus, Portulaca oleracea

\section{Introduction}

The effect of weed interference on crop yield is frequently presented only in terms of weed density. However, the relationship between crop yield loss and weed density varies with the influence of management practices and environmental factors on crop-weed competition (Lindquist, 2001). Better understanding of competition processes can be used to predict the effects of management and to identify plant characteristics related to competitive ability (Bastiaans et al., 1997). This is difficult to achieve by empirical experiments alone because plant competition involves complex physiological processes that regulate resource acquisition, conversion of resources to plant biomass and response of plants to resource availability (Lindquist, 1997). Ecophysiological simulation models provide a quantitative method to integrate and understand these processes. INTERCOM (INTERplant COMpetition) was developed to contribute towards a better understanding of crop-weed competition (Kropff \& Van Laar, 1993).

The INTERCOM model was first developed to simulate competition between Beta vulgaris and Chenopodium album (Kropff \& Van Laar, 1993), and later modified to 
simulate competition between Oryza sativa and Echinochloa crus-galli (Lindquist \& Kropff, 1996) and between Zea mays and Abutilon theophrasti (Lindquist, 2001). In the model, growth of each species is dependent upon the amount of resources garnered and the efficiency with which the crop or weed converts those resources into growth. When water and nutrients are provided in sufficient quantities, the outcome of competition is determined by competition for light. In this situation, daily gross $\mathrm{CO}_{2}$ assimilation are calculated based on plant population density, plant phenological development, plant physiological and morphological characteristics, location, latitude and weather data. The net carbohydrate gain after respiration is then partitioned to different organ groups. New leaf biomass is multiplied with specific leaf area (SLA) to obtain new leaf area. The increased leaf area is used to calculate $\mathrm{CO}_{2}$ assimilation of the next day (Kropff \& Van Laar, 1993).

Cowpea (Vigna unguiculata (L.) Walp) is an important warm-season and nitrogen-fixing cover crop, particularly in organic vegetable production systems in the USA (Creamer \& Baldwin, 2000; Ehlers et al., 2002). Because weed control is one of the costlier components of vegetable production (Mayberry et al., 1995), the ability of cowpea cover crops to suppress weeds. is a critical component in making cover crop systems practical. Substantial differences in plant growth habit exist among cowpea varieties, from genotypes that grow completely prostrate to very erect. However, little is known of how these differences might impact on competitiveness with weeds. For example, prostrate varieties more rapidly produce ground cover than tall erect varieties; however, if weeds. can grow through the thinner, spreading leaf canopy, they may have more access to light than when they are competing with a tall, erect variety.

An ideal experimental design to study the effects of growth habit on competitiveness with weeds. would use near isogenic lines that differ only in growth habit. Unfortunately, isogenic cowpea lines differing only in growth habit do not exist. Another possible experimental approach would be to use several genotypes of each of the three growth habits (erect, semi-erect and prostrate) to generate average competitiveness of each growth habit. However, the number of treatments and replications needed for such a labor intensive experiment is impractical and would require several field seasons to complete. When experimental approaches are either not available or impractical, computer simulation models can be used to simulate cowpea genotypes with different growth habits and to compare the competitiveness of these genotypes. Model predictions can then be applied to select a reduced, more optimal number of treatments to make potentially difficult breeding experiments more manageable. The same approach can be applied to study other traits of interest to crop breeders and how these traits (e.g. yield) might interact with competitive ability.

We used cowpea genotypes that are similar in most characteristics but differ substantially in growth habit, i.e. the erect genotype IC, semi-erect genotype 288 and prostrate genotype 779 . Because the competitive ability of a given trait is significantly affected by the associated weed species (Callaway \& Forcella, 1993), each cowpea genotype was grown in an additive design with common sunflower (Helianthus annuus L.) and common purslane (Portulaca oleracea L.), two weeds. of contrasting stature. The INTERCOM simulation model was then used as a tool to study the competitiveness of cowpea genotypes with different growth habits. The model was parameterized and calibrated for cowpea and weed growth in monoculture, validated with the results of the additive competition experiment and then used to simulate nearly isogenic cowpea varieties to gain insight on how growth type affects competitive outcome.

\section{Materials and methods}

Field experiments were conducted at the University of California Citrus Research Center in Riverside $\left(33^{\circ} 58^{\prime} \mathrm{N}\right.$, $117^{\circ} 20^{\prime} \mathrm{W} ; 311 \mathrm{~m}$ above sea level) during the summers of 2003 and 2004 on an Arlington loam soil with a pH 7.3 and about $3 \%$ organic matter. The field was fallow for two years before the experiment. Mean daily temperature during the summer growing season varied from 20 to $31^{\circ} \mathrm{C}$. There was no rain during the growing seasons and all experiments were drip irrigated.

The three cowpea genotypes used in the study were erect "Iron-Clay" (IC), semi-erect "IT89KD-288" (288), and prostrate "UCR 779" (779). These cowpea genotypes have similar growth vigor and biomass production but different growth habit (Wang et al., 2004). Sunflower and purslane were chosen to represent a tall and a short stature weed.

\section{Monoculture experiment and model parameterization}

A field experiment designed to characterize the growth of three cowpea genotypes, sunflower and purslane in monoculture was conducted in 2003 and 2004. INTERCOM parameters were measured in the experiment. The biomass and leaf area growth data of each species were used to calibrate the INTERCOM model in the monoculture situation. The experiment included 11 treatments: three cowpea genotypes planted at a density of 17 plants per $\mathrm{m}^{2}$, sunflower at densities of $1.3,4,8,16$ 
plants per $\mathrm{m}^{2}$ in 2003 and $0.5,1.3,4,8$ plants per $\mathrm{m}^{2}$ in 2004 and purslane at densities of 4, 16, 32, >64 plants per $\mathrm{m}^{2}$ in both years.

The experiment was a randomized complete block design with four replications. Each replicate was composed of four rows of raised beds, each $9.1 \mathrm{~m}$ long with $0.76 \mathrm{~m}$ bed spacing. Prior to planting, $224 \mathrm{~kg} \mathrm{ha}^{-1}$ synthetic fertilizer (N:P:K $=15: 15: 15)$ were broadcast over the field and incorporated into the soil by disking. A similar amount of fertilizer was applied on the shoulders of each raised bed 1 month after planting.

Cowpea and sunflower seeds. were planted into dry soil on July 3, 2003. Purslane was planted into crop rows by hand on July 7, 2003 and then the field was immediately irrigated. In 2004, cowpeas and sunflower were planted on June 29 and the field was watered on June 30 after purslane was planted. The field was drip irrigated for $2 \mathrm{~h}$ three times per week in both years to prevent water stress. All other weed species were removed by hand throughout the growing seasons.

Cowpea and weed plants were sampled weekly, beginning 2 weeks after planting until final biomass harvest in both years. One meter of row $\left(0.76 \mathrm{~m}^{2}\right)$ was harvested at each sampling date by cutting plants at the soil surface. The number of cowpea or weed plants was counted and plants were dried at $70^{\circ} \mathrm{C}$ with ventilation to achieve constant weight. In four of the harvests in 2003 and two in 2004, leaves and stems of each species were separated and the leaf area of fresh green leaves was measured with an optical leaf area meter. Dry weight of leaves and stems were also measured.

In addition to the measurements described above, the following information also was obtained during each of the growing seasons.

\section{Initial parameters}

On the day of emergence, height of 20 plants of each species or genotype was measured from the soil surface to the highest standing point of each plant. The plants were clipped at the soil surface and roots were excavated to a depth of $30 \mathrm{~cm}$ with a shovel and gently washed in a bucket of water. Samples were brought to the laboratory and leaves were separated from stem by clipping them at the attachment of the lamina to the petiole. Initial leaf area of each species or genotype for the INTERCOM model was measured. Initial leaf, stem and root dry weight were obtained after plants were dried at $70^{\circ} \mathrm{C}$ to constant weight with ventilation.

\section{Development rate}

Plant development stage was represented as a dimensionless scale, where 0 was assigned at plant emergence,
1 at flowering (sunflower at head emergence) and 2 at seed maturity. Development was quantified as the number of growing day degrees $\left(\mathrm{d}^{\circ} \mathrm{C}\right)$ accumulated after plant emergence to a particular stage. Data were calculated using the single-sine method (Zalom et al., 1983). The base temperatures for cowpea $\left(8.5^{\circ} \mathrm{C}\right)$, sunflower $\left(7^{\circ} \mathrm{C}\right)$ and purslane $\left(7.7^{\circ} \mathrm{C}\right)$ were based on the results published by Robinson (1971), Hall (2001) and Steinmaus et al. (2000). The development rate in the vegetative phase was calculated as the reciprocal of total $\mathrm{d}^{\circ} \mathrm{C}$ accumulated from plant emergence to flowering and the development rate in the reproductive phase was calculated as the reciprocal of $\mathrm{d}^{\circ} \mathrm{C}$ from plant flowering to seed maturity.

\section{Partitioning coefficients}

Estimates of dry matter partitioning coefficients were obtained from six sample dates in 2004. The procedures used in measuring initial parameters were repeated for the first and second sampling. For the third to sixth sampling, those same procedures for stem and leaves were followed. Because it was difficult to collect all the fine root in the field, only tap roots were sampled and the total plant root biomass was estimated using fine root: tap root ratios obtained from plants sown on the same day as field planting and grown in $20 \mathrm{~L}$ plastic pots with soil from the same field (Hall et al., 1985, 1990). The pots were put in an open area and watered daily with fertilizer enriched water. On the same sampling day for field plants, four potted plants were washed carefully free of soil and tap and fine roots were separated. The total root biomass for field plants was then estimated using tap root:fine root ratios from potted plants.

The partitioning coefficients for an organ (e.g. leaf) were calculated by dividing the change in weight between two sampling dates by the total change in weight of whole plants. If the change in weight or total weight was less than zero, the partitioning coefficient was set to zero. The development stage was defined as the midpoint of the period between two sampling dates (Kropff \& Van Laar, 1993).

\section{Relative growth rate of leaf area and specific leaf weight}

Leaf area expansion is often exponential when LAI is less than 0.6 (Lindquist, 1997). The estimation of relative growth rate of leaf area (RGRL) is described elsewhere (Wang, 2005). After LAI is greater than 0.6, leaf area increase was calculated by dividing leaf biomass by specific leaf weight (SLW, the ratio of leaf biomass and leaf area), where leaf biomass was determined by total biomass increase and partitioning coefficients (Kropff \& Van Laar, 1993). Estimates of SLW at each harvest date were obtained from the ratio of leaf biomass to leaf area. 


\section{Plant height growth}

Plant height of each species was measured six times in 2003 and seven times in 2004. The logistic growth model was fitted to plant height (HT) against day degrees (DD) (Christensen, 1995):

$$
\mathrm{HT}(\mathrm{DD})=\frac{H_{m}}{1+\exp \left(H_{a}-H_{b} \mathrm{DD}\right)}
$$

where $H_{m}$ is plant maximum height, $H_{a}$ and $H_{b}$ are shape parameters.

\section{Leaf area distribution}

Leaf area distribution over plant height was measured when flower buds were seen in the field. Ten plants of each species were harvested from monoculture plots in each year. Plants were separated at $20-\mathrm{cm}$ intervals from the top of the canopy to the ground. Relative leaf area index in each layer $\left(\mathrm{LAI}_{\mathrm{r}}=\right.$ leaf area in each layer divided by total leaf area) was measured and data were quantified as a function of relative plant height $\left(\mathrm{HT}_{\mathrm{r}}=\right.$ height of a layer divided by total height $)$ according to Lindquist and Mortensen (1999):

$$
\mathrm{LAI}_{\mathrm{r}}=1-\exp \left(-\left(\left(\frac{1-\mathrm{HT}_{\mathrm{r}}}{\mathrm{LDa}}\right)^{\mathrm{LD}_{\mathrm{b}}}\right)\right)
$$

where $1-\mathrm{LD}_{\mathrm{a}}$ is the relative height at which maximum leaf area density occurs, and $\mathrm{LD}_{\mathrm{b}}$ is the slope of the curve through the inflection point.

\section{Other INTERCOM parameters}

The parameters used for calculating $\left[\mathrm{CO}_{2}\right]$ assimilation rate and light use efficiency are described elsewhere (Wang, 2005). Several INTERCOM parameters were difficult to measure experimentally and were obtained from the literature. Maintenance respiration parameters were taken from Spitters et al. (1989) and assimilation requirement parameters from Penning de Vries et al. (1989). The effects of temperature on initial light use efficiency were estimated from the results of Ehleringer and Pearcy (1983). Tissue senescence, carbon re-allocation and the maximum assimilation rate of stem and reproductive tissue were obtained from limited data or estimated from various published resources (Lindquist, 1997; Schneiter, 1997).

\section{Competition experiment}

A second experiment was conducted to determine yield reduction in the three cowpea genotypes grown in competition with a range of common sunflower or common purslane densities in an adjacent field in 2003 and 2004. The cowpea genotypes were planted alone and in mixture with sunflower or purslane at the four densities described in the first experiment. Experimental design, plot size and field management were the same as the monoculture experiment described above.

One meter of row $\left(0.76 \mathrm{~m}^{2}\right)$ was sampled weekly, beginning 2 weeks after planting until final biomass harvest. The numbers of cowpea and weed plants were counted and plant biomass was measured. In four harvests in 2003 and two harvests in 2004, leaf area of fresh green leaves was also measured. The biomass and leaf area growth data of each species under competition were compared with INTERCOM simulation results of cowpea weed competition.

\section{INTERCOM simulations}

After deriving all of the parameters for the INTERCOM model, the model was calibrated using monoculture plant growth data. The INTERCOM model satisfactorily simulated monoculture plant growth data after some minor adjustments of partitioning and leaf death rate parameters. The derived parameter sets were used to test the model performance in simulating competition of cowpea and sunflower or purslane.

The INTERCOM model for mixture of cowpea genotypes and sunflower was validated and used to compare the competitive ability of cowpea growth habit when cowpeas were grown with sunflower. To do so, we assumed that growth habit is controlled mainly by height growth $\left(H_{m^{\prime}} H_{a^{\prime}} H_{b}\right)$ and leaf area distribution $\left(\mathrm{LD}_{\mathrm{a}^{\prime}} \mathrm{LD}_{\mathrm{b}}\right)$ of plants [Table 1 , full details of the growth parameters of the three genotypes can be found in Wang et al.

Table 1. Parameter estimates of plant height growth and leaf area distribution of three cowpea genotypes, sunflower and purslane

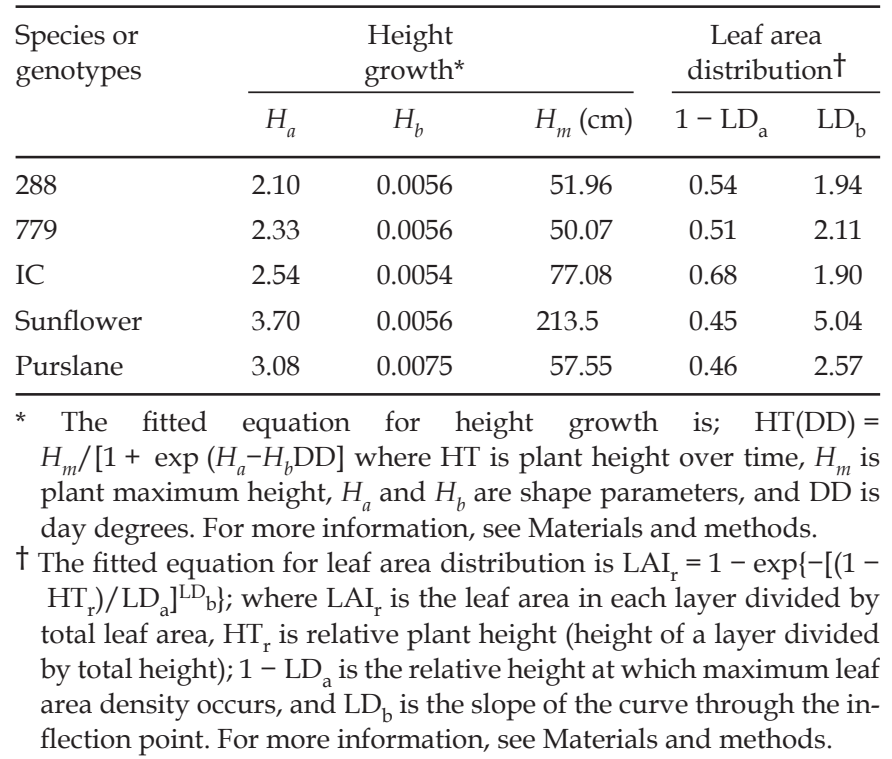


(2006a)]. Intermediate semi-erect 288 was used as a standard cowpea genotype. A theoretical erect genotype was constructed by replacing the above height growth and leaf area distribution parameters of 288 by that of genotype IC, and a theoretical prostrate genotype was constructed by replacing the above parameters by that of genotype 779. These simulated isogenic cowpea lines differed in growth habit but were otherwise identical. The three theoretical cowpea genotypes were used in the INTERCOM model to simulate cowpea-sunflower competition and model output (both cowpea and sunflower biomass) was compared with measured results of the mixture experiment to determine the competitive ability of cowpea height and leaf area distribution. Weather data for 2003 was used in all the INTERCOM simulations.

The effect of height growth or leaf area distribution was also studied by changing either height growth or leaf area distribution in the above-constructed theoretical cowpea genotypes. The change in either cowpea or sunflower biomass was expressed as the difference between the erect genotype and the prostrate genotype, or the difference between the semi-erect genotype and the prostrate genotype.

\section{Statistical analysis}

Cowpea biomass loss in relation to weed density was characterized by fitting the model proposed by Cousens (1985) to measured biomass loss:

$$
Y_{\text {loss }}=\frac{I d}{1+(I d / A)}
$$

where $Y_{\text {loss }}$ is the percent cowpea biomass loss calculated as $Y_{\text {loss }}=\left(Y_{\text {mono }}-Y_{\text {mix }}\right) / Y_{\text {mono }} Y_{\text {mono }}$ and $Y_{\text {mix }}$ are cowpea biomass in monocultures and mixtures, respectively, $d$ is the weed density, $A$ is the asymptotic value of yield loss at high weed density and $I$ [\% (plants per $\left.\left.\mathrm{m}^{2}\right)^{-1}\right]$ is the biomass loss per unit weed density as weed density approaches zero. $A$ and $I$ are parameters to be estimated. Greater values of coefficients $A$ and $I$ indicate greater weed competition or reduced crop tolerance to competition.

INTERCOM model performance was evaluated using the modeling efficiency equation (ME, Janssen \& Heuberger, 1995):

$$
\mathrm{ME}=\frac{\sum_{i=1}^{n}\left(O_{i}-O_{m}\right)^{2}-\sum_{i=1}^{n}\left(P_{i}-O_{i}\right)^{2}}{\sum_{i=1}^{n}\left(O_{i}-O_{m}\right)^{2}}
$$

where $P_{i}$ and $O_{i}$ denote predicted and measured values at sampling time $i$, and $O_{m}$ is the mean of measured values for all sampling times. High ME values (close to 1) indicate accurate model predictions. A negative value of ME indicates that the model predicts less accurately than the overall mean of all field observations.

INTERCOM model performance was also evaluated by a linear regression of INTERCOM model output for biomass or LAI with measured biomass:

$$
Y=c X
$$

where $Y$ is the predicted value and $X$ is the measured value and the regression line was forced through the origin. A perfect simulation results in slope $c=1$.

\section{Results}

Plant biomass and LAI of all three cowpea genotypes together, sunflower and purslane grown in monoculture were simulated satisfactorily using INTERCOM (Figure 1). The slope of a linear regression between predicted and measured biomass and LAI does not differ from 1.0, indicating accurate prediction of monoculture growth of the three plant species.

INTERCOM did not adequately predict cowpea biomass and LAI in competition with purslane. The regression of predicted and measured cowpea biomass showed that INTERCOM overestimated the field observations by 19\% (Figure 2). INTERCOM predicted larger
Figure 1. Measured biomass and LAI and as predicted by INTERCOM for three cowpea genotypes, sunflower and purslane grown in monoculture. The regression line of predicted values vs. measured values was forced through the origin. The regression line is $y=0.978 x$ with $r^{2}=0.97$ for biomass and $y=0.987 x$ with $r^{2}=0.88$ for LAI, where $y$ is the predicted and $x$ is the measured value.
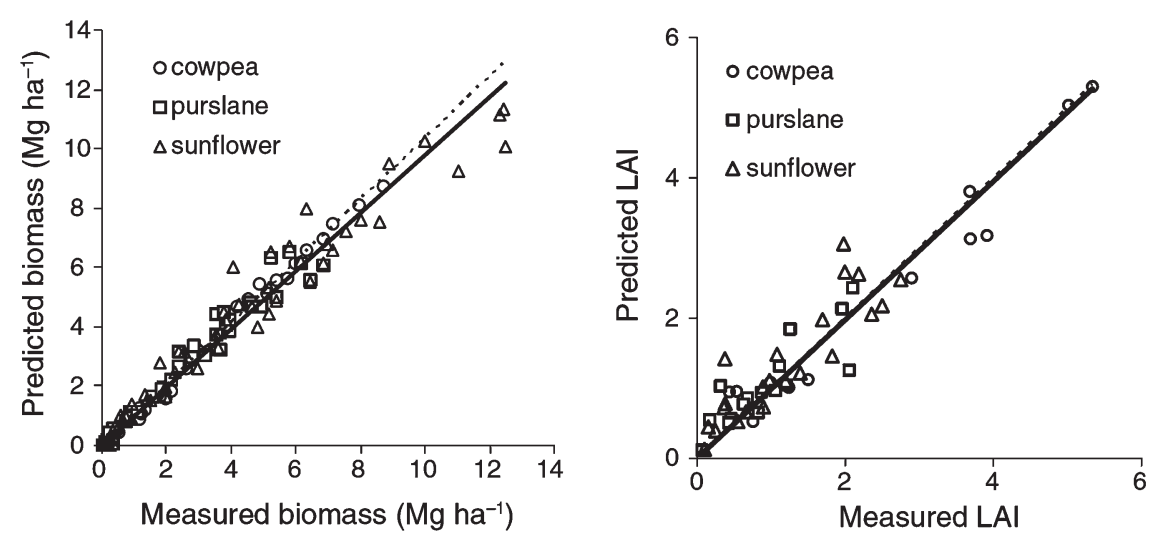

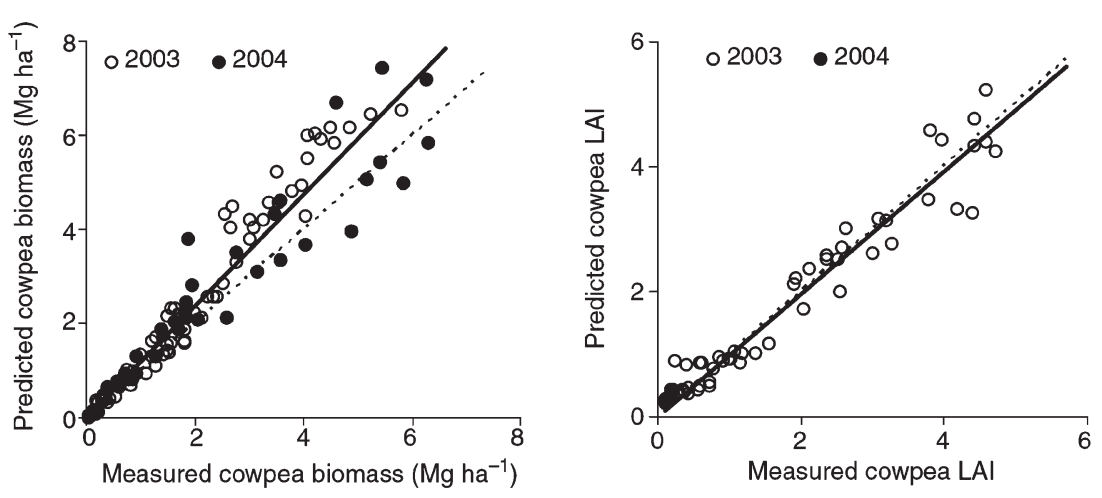

Figure 2. Measured biomass and LAI and as predicted by INTERCOM for three cowpea genotypes and purslane grown in mixture. The LAI of cowpea and purslane was only measured twice in the early growing season of 2004. The regression line of predicted values vs. measured values was forced through the origin.
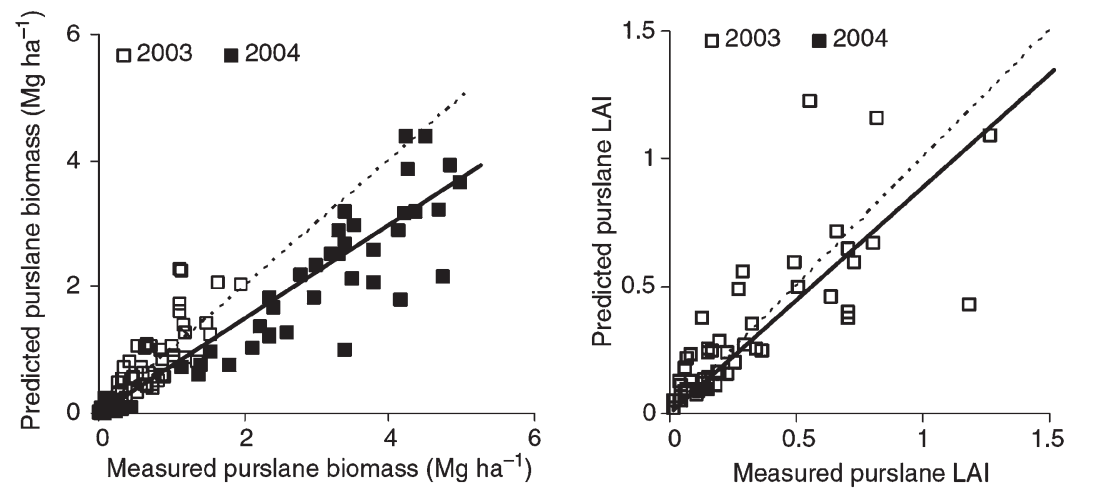

purslane biomass than measured in 2003, but smaller purslane biomass in 2004. Predicted purslane biomass was only 76\% of measured biomass for 2003 and 2004 combined. While the simulation of cowpea LAI was accurate, there was high variation in the model predictions of purslane LAI (Figure 2). The regression of predicted vs. measured purslane LAI had a slope of 0.89 with $r^{2}=0.58$.

The ME for predicting cowpea biomass production when competing with purslane ranged from 0.42 to 0.90 in 2003 and 2004, with seven MEs out of 21 smaller than 0.7 (Table 2). The predictions for purslane biomass had eight MEs out of 21 smaller than 0.7 and two of them smaller than zero. This indicates poor predictions of cowpea and purslane biomass for some cowpea genotypes and some purslane densities. The simulations of competition of genotype 288 with purslane are better than that of genotype 779 and IC with purslane.

Cowpea and sunflower biomass and LAI grown in competition were accurately predicted by INTERCOM

Table 2. Modeling efficiency (ME) calculated for simulated vs. measured cowpea and weed aboveground biomass throughout the growing season

\begin{tabular}{|c|c|c|c|c|c|c|c|c|}
\hline \multirow[t]{2}{*}{ Weed } & \multirow[t]{2}{*}{ Year } & \multirow{2}{*}{$\begin{array}{l}\text { Weed density } \\
\text { (plants per } \mathrm{m}^{2} \text { ) }\end{array}$} & \multicolumn{2}{|c|}{288 with weed } & \multicolumn{2}{|c|}{779 with weed } & \multicolumn{2}{|c|}{ IC with weed } \\
\hline & & & 288 & Weed & 779 & Weed & IC & Weed \\
\hline \multirow[t]{5}{*}{ Purslane } & \multirow[t]{3}{*}{2003} & 4.2 & 0.90 & 0.77 & 0.69 & 0.61 & 0.89 & 0.86 \\
\hline & & 29.5 & 0.80 & 0.97 & 0.64 & -0.45 & 0.43 & 0.70 \\
\hline & & 93.2 & 0.89 & 0.87 & 0.87 & -1.22 & 0.69 & 0.85 \\
\hline & \multirow[t]{2}{*}{2004} & 15.1 & 0.98 & 0.72 & 0.97 & 0.74 & 0.77 & 0.28 \\
\hline & & 75.8 & 0.93 & 0.86 & 0.99 & 0.91 & 0.42 & 0.51 \\
\hline \multirow[t]{5}{*}{ Sunflower } & \multirow[t]{4}{*}{2003} & 1.4 & 0.97 & 0.78 & 0.95 & 0.97 & 0.94 & 0.99 \\
\hline & & 4.1 & 0.85 & 0.98 & 0.88 & 0.93 & 0.69 & 0.96 \\
\hline & & 8.3 & 0.82 & 0.97 & 0.86 & 0.96 & 0.69 & 0.99 \\
\hline & & 14.7 & 0.69 & 0.93 & 0.93 & 0.92 & 0.82 & 0.87 \\
\hline & 2004 & 1.5 & 0.98 & 0.34 & 0.92 & 0.46 & 0.98 & 0.91 \\
\hline
\end{tabular}

The average density for cowpeas was 18.9 plants per $\mathrm{m}^{2}$ in 2003 and 15.6 plants per $\mathrm{m}^{2}$ in 2004. 
Figure 3. Measured biomass and LAI and as predicted by INTERCOM for three cowpea genotypes and sunflower grown in mixture. The LAI of cowpea and sunflower was only measured three times in the early growing season of 2004. The regression line of predicted values vs. measured values was forced through the origin.
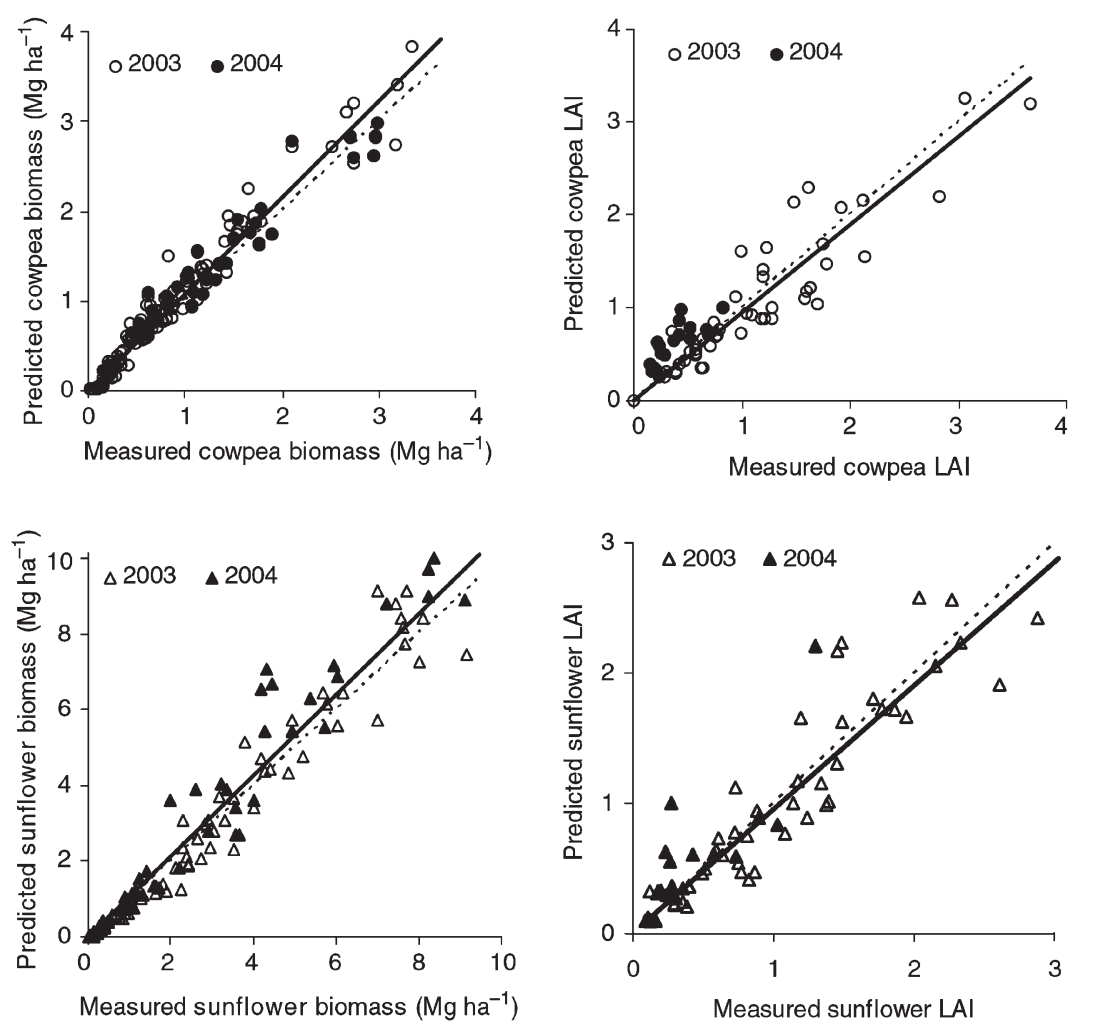

(Figure 3); the regression slope did not differ from 1.0. ME values for cowpea and sunflower biomass production in competition ranged from 0.69 to 0.98 (Table 2), indicating good prediction of field observations.

INTERCOM was then used to simulate how changing sunflower density affected cowpea percentage biomass loss in 2003 and 2004. Equation 3 was fitted to the simulated data and compared with measured biomass loss data. INTERCOM accurately predicted cowpea yield loss for genotype 288, but slightly underpredicted biomass loss at low weed densities and overpredicted biomass loss at high weed density for genotype 779 and IC (Figure 4).

The model was used to compare the effect of growth habit on crop competitive ability with weeds. (Figure 5). Simulation results suggest that the erect genotype has larger biomass than semi-erect and prostrate genotypes when cowpea is grown alone. When grown with sunflower, the erect genotype has a larger competitive advantage than semi-erect and prostrate genotypes. The erect genotype produces more cowpea biomass and causes a greater reduction in sunflower biomass than either the semi-erect or the prostrate genotypes. The semierect genotype is slightly more competitive than the prostrate genotype. As sunflower density increases from 1 to 4 plants per $\mathrm{m}^{2}$, the differences between growth habits are smaller.

Replacing only height growth or leaf area distribution in the constructed theoretical cowpea genotypes showed that changing height growth or leaf area distribution from semi-erect to erect increased cowpea biomass and decreased sunflower biomass. Sunflower growth increased when cowpea height or leaf area distribution changed from semi-erect to prostrate (Figure 6). Cowpea leaf area distribution had similar effect on cowpea biomass production with cowpea height growth when grown with sunflower. However, cowpea leaf area distribution had much smaller effects on sunflower biomass production compared with cowpea height growth.

\section{Discussion}

Crop variety differences in competitive ability with weeds. could be exploited through plant breeding to develop highly competitive varieties that resist yield losses from weed competition and suppress weed biomass and seed production (Callaway, 1992). When competitive varieties are used, they can reduce crop yield loss and herbicide use (Christensen, 1994; Lemerle et al., 1996; Lindquist \& Mortensen, 1998; Hutchison \& McGiffen, 2000). However, breeding competitive varieties requires an understanding of crop-weed competition and ranking of competitive ability for a given trait. Model simulations provide a valuable approach to help breeders (Bastiaans et al., 1997).

Computer simulation of plant competition can integrate environmental factors, management practices, and plant morphology and physiology into one framework to study plant competition (Kropff \& Van Laar, 1993). 

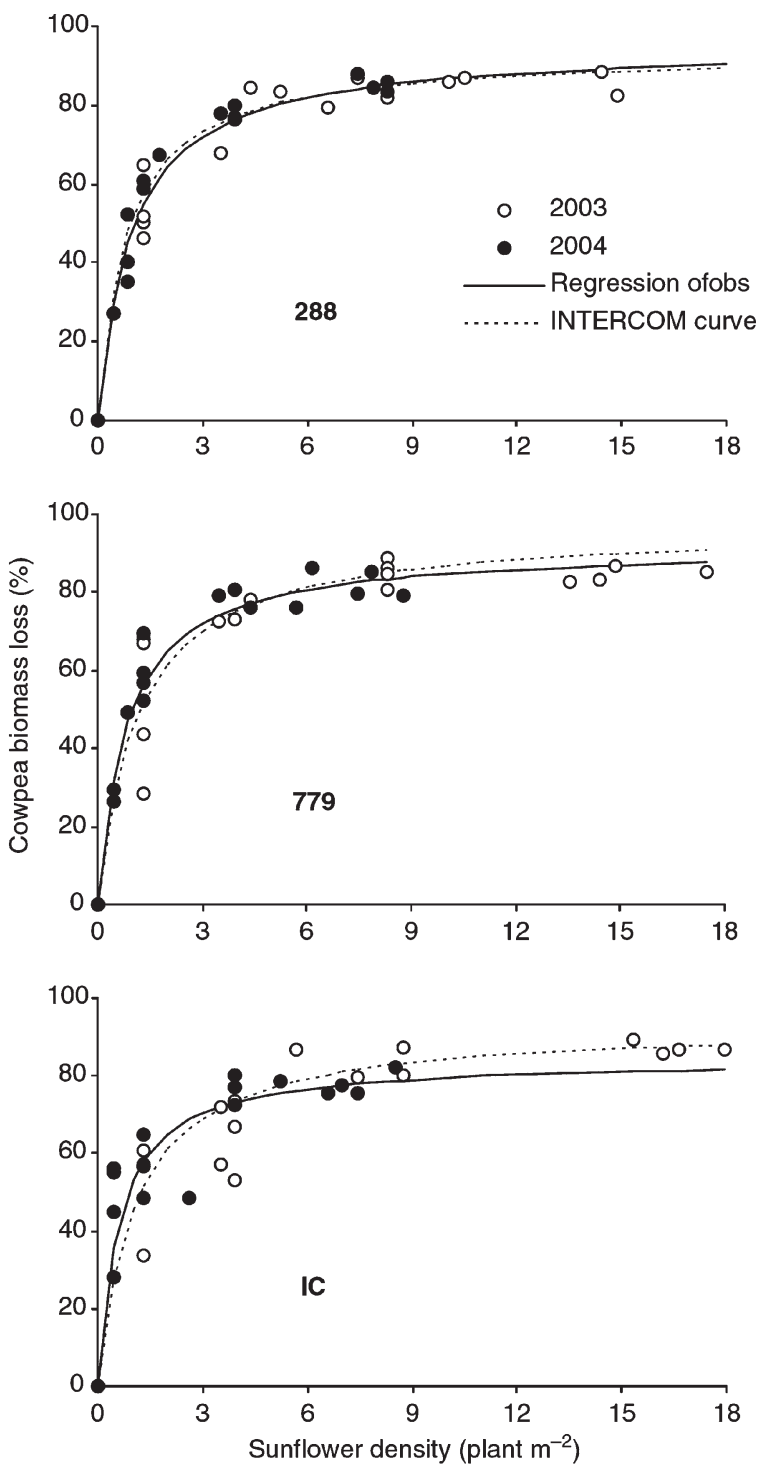

Figure 4. The effects of sunflower density on the percent biomass yield loss of cowpea genotype 288, 779 and IC. The symbols are measured percent biomass yield loss of cowpea genotypes in 2003 and 2004. The solid line is the fitted regression equation of data by the hyperbolic model. The dashed line is cowpea percent biomass loss predicted by INTERCOM model.

Thus, simulation models would help breeders in choosing crop traits that are more competitive with weeds. These models can also be used to predict the results crop breeders would obtain, if a specific trait or several traits are changed. The simulation models could help design experiments to test-specific traits and could reduce the size of experiments by suggesting a more optimal selection of treatment variables. In this study, we were able to use INTERCOM as a tool to expand on field observations to examine questions of weed competition that would have been difficult to explore experimentally; i.e. create hypothetical isogenic lines that differed only in growth habits and use them to examine how growth
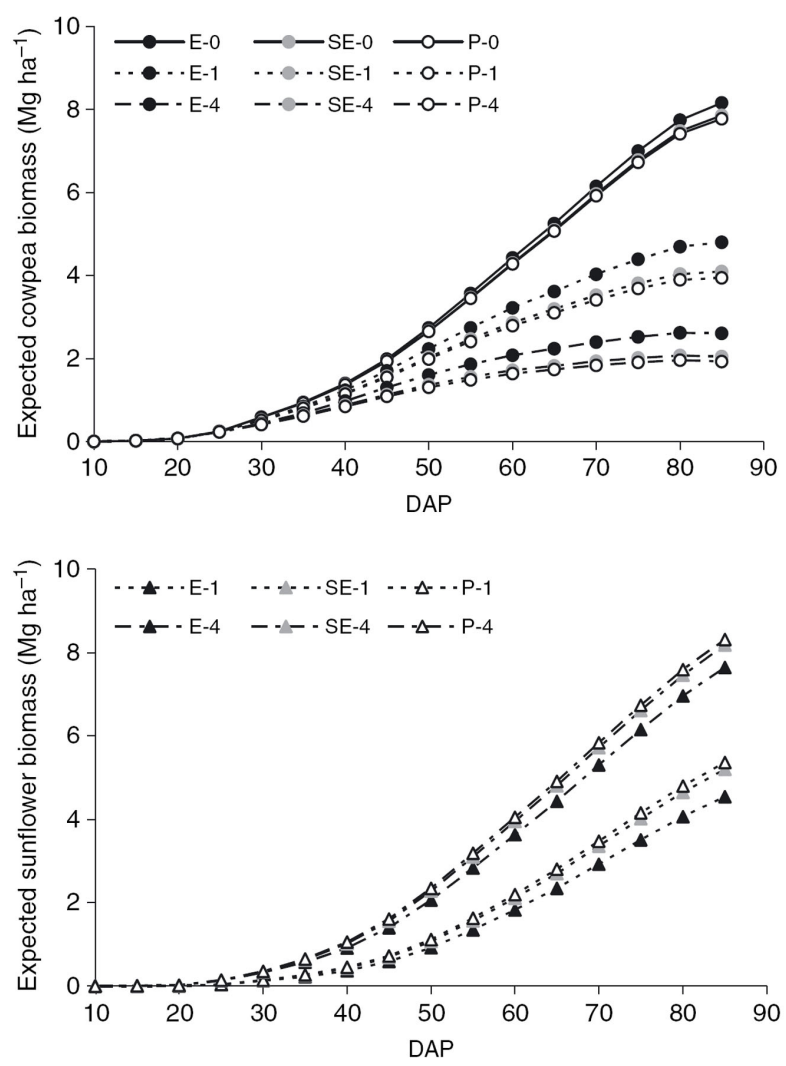

Figure 5. INTERCOM-simulated biomass growth of three theoretical cowpea genotypes and sunflower when cowpea and sunflower are grown in mixture. Growth parameters of semierect 288 were used for the three theoretical cowpea genotypes, except canopy structure and crop height growth characteristics, for which IC, 288 and 779 were used for erect (E), semierect $(\mathrm{SE})$ and prostrate $(\mathrm{P})$ genotypes respectively. The numbers following E, SE and P are sunflower densities in plants per $\mathrm{m}^{2}$. The mean densities of genotype 288 measured in the field experiments were used. Weather data for 2003 was used in INTERCOM simulations.

habit affects competition. Using many genotypes to measure the average competitiveness of each growth habit would require very large experiments, especially if several weeds. with different statures and several weed densities are tested. Using our approach, smaller field experiments can be used to confirm the specific inferences gained from simulation studies.

The same approach can be used to study other traits that affect plant growth and competition. The other possible cowpea traits are early leaf growth rate (RGRL), leaf thickness (SLW), initial plant size, emergence rate and development rate. The development rate could be used to compare the effect of maturity time on crop competitive ability with weeds, which is controversial in the literature (Callaway, 1992). The possible management practices that could be studied include crop density, weed type and species, weed density and/or weed emergence time (Wang, 2005). 

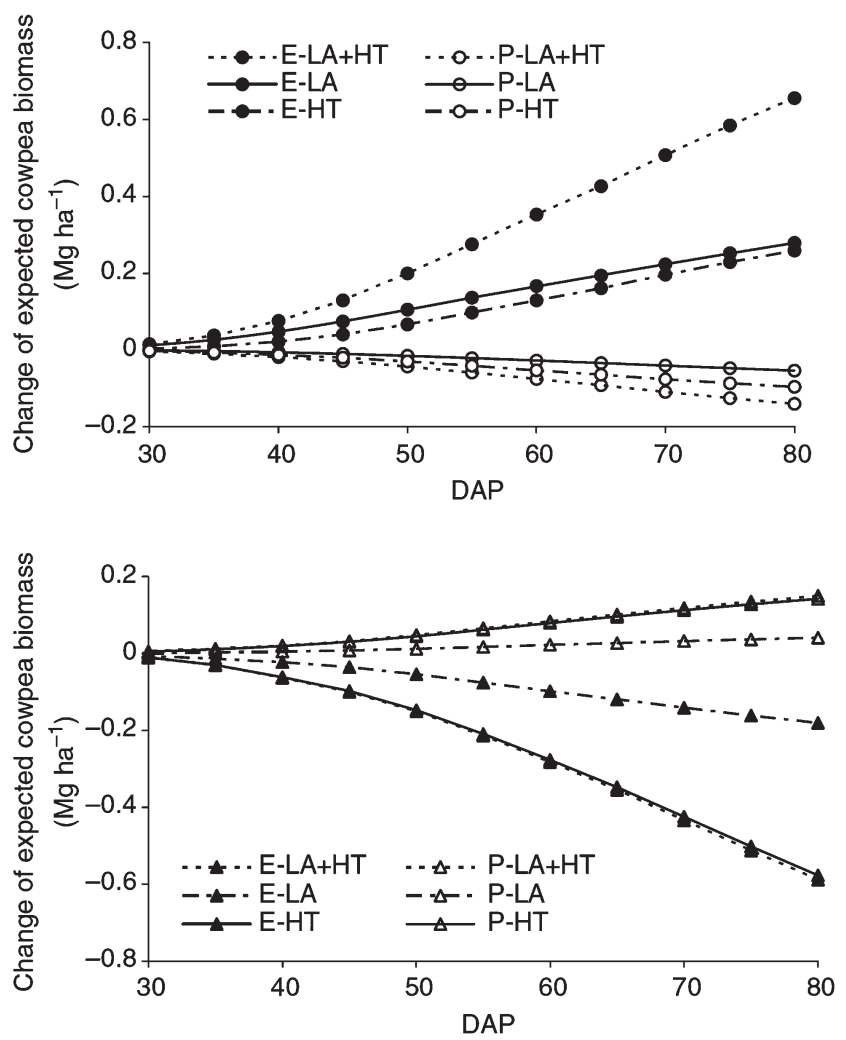

Figure 6. The effects of cowpea leaf area distribution and/or height growth on the biomass of cowpea and sunflower. Semierect 288 was used as a standard cowpea genotype. Biomass changes of cowpea [erect $(\mathrm{E})$ and prostrate $(\mathrm{P})$ ] and sunflower were based on that of semi-erect genotype 288 LA and HTs.

In this study, we assume that erect, semi-erect and prostrate growth habit of cowpea genotypes are determined by height growth and leaf area distribution. The other factors might play a role in determining growth habit, for example, partitioning coefficients. However, growth analysis of 18 cowpea genotypes with different growth habit in a field trial has showed that the growth habit is mainly determined by height growth and leaf area distribution (G. Wang, unpubl. obs.).

Competitiveness is a key component of cover crop value. From our work, it appears that development of cowpea cover crops with erect stature would be recommended where weed competitiveness is important. The simulation results agree with previous field and green house experiments (Wang et al., 2004, 2006b). The erect genotype is taller and the relative height at which maximum leaf area density occurs is higher; the result is a canopy that intercepts more light when competing with weeds. These results are similar to a previous study that found that staked cowpeas are more competitive than prostrate cowpeas (Nangju, 1978). The ability to rapidly form a tall canopy has also been shown to provide a competitive advantage in a diverse array of other crops
(Berkowitz, 1988; Callaway, 1992; Bastiaans et al., 1997). Varieties with erect growth habits have other practical advantages, including late season cultivation without disrupting the crop canopy. Other leguminous cover crop species also have erect to prostrate growth habit and it is interesting to note that recent work on chickpea (Paolini et al., 2006) indicates that taller varieties are more competitive. The effect of cowpea growth habit on the biomass of cowpea and sunflower decreases as sunflower density increases. This suggests that a competitive cowpea cover crop may outcompete a tall competitor at low density, but may require supplemental control measures when weed density is high.

INTERCOM did not accurately simulate competition between cowpea and purslane. INTERCOM does not consider potential changes in physiology and morphology that could occur as species go from monoculture to mixtures (Kropff \& Van Laar, 1993). This may have affected the simulation of competition of cowpea and purslane more than that of cowpea and sunflower. Because cowpea stature is more similar to that of purslane than it is to sunflower, purslane was probably more affected by cowpea competition for light. The competition of cowpea and purslane was also affected significantly by field site variability, as shown by the large variance in cowpea and purslane biomass measured in the competition experiments.

INTERCOM uses the same light extinction coefficient $k$ for all canopy layers and cowpea genotypes. However, the value of $k$ could vary with canopy layer, because layers of leaves may have different leaf orientation or leaf angle distribution. Coefficient $k$ may also vary with genotype due to variations in canopy structure between the three growth habits. Potential model bias due to the assumption of a constant $k$ value was investigated through sensitivity analysis (G. Wang \& M. E. McGiffen, unpubl. obs.). However, moderate changes in $k$ caused small changes in model predictions, e.g. $15 \%$ change in $k$ caused less than $4 \%$ change in either biomass or leaf area of cowpea or sunflower. While the change in model predictions was numerically small for all genotypes, the prostrate and semi-erect genotypes were more affected than the erect genotype; the relative competitive ability of the three cowpea growth habits remained unchanged regardless of the value of $k$.

Leaf spatial distribution was a potential source of model error that is not considered by the INTERCOM model. This could result in potential bias of simulation results due to spatial heterogeneity caused by the different canopy structure of the three cowpea growth habits. More field experiments and changes to competition models are needed to account for the potential effects of genotype-specific variation in $k$ and leaf spatial distribution. 


\section{Acknowledgments}

This research was funded by the Western Region Sustainable Agriculture Research and Education grant "The Development and Dissemination of a Cowpea Cultivar for Cover Crops." The Agricultural Operations staff at the University of California, Riverside, helped field plot establishment and maintenance. We thank Eddie Ogbuchiekwe for his help in field management, Dr. Jodie Holt and Dr. Edith Allen of University of California, Riverside, for reviewing the first manuscript and providing useful suggestions.

\section{References}

Bastiaans L, Kropff MJ, Kempuchetty N, Rajan A, \& Migo TR (1997) Can simulation models help design rice cultivars that are more competitive against weeds? Field Crops Research 51, 101-111.

Berkowitz A (1988) Competition for resources in weed-crop mixtures. In: Weed Management in Agroecosystems: Ecological Approaches (eds. MA Altieri \& M Liebman), 89119. CRC Press, Boca Raton, FL, USA.

Callaway MB (1992) A compendium of crop varietal tolerance to weeds. American Journal of Alternative Agriculture 7, 169-180.

Callaway MB \& Forcella F (1993) Crop tolerance to weeds. In: Crop Improvement for Sustainable Agriculture (eds. MB Callaway \& CA Francis), 100-131. University of Nebraska Press, Nebraska, USA.

Christensen S (1994) Crop weed competition and herbicide performance in cereal species and varieties. Weed Research 34, 29-37.

Christensen S (1995) Weed suppression ability of spring barley varieties. Weed Research 35, 241-247.

Cousens R (1985) A simple model relating yield loss to weed density. Annals of Applied Biology 107, 239-252.

Creamer NG \& Baldwin KR (2000) An evaluation of summer cover crops for use in vegetable production systems in North Carolina. HortScience 35, 600-603.

Ehleringer J \& Pearcy RW (1983) Variation in quantum yield for $\mathrm{CO}_{2}$ uptake among $\mathrm{C}_{3}$ and $\mathrm{C}_{4}$ plants. Plant Physiology $73,555-559$.

Ehlers JD, Fery RL, \& Hall AE (2002) Cowpea breeding in the USA, new varieties and improved germplasm. In: Challenges and Opportunities for Enhancing Sustainable Cowpea Production (eds. CA Fatokun, SA Tarawali, BB Singh, PM Kormawa, \& M Tamo), 62-77. International institute of Tropical Agriculture, Ibadan, Nigeria.

Hall AE (2001) Crop developmental responses to temperature, photoperiod, and light quality. In: Crop Response to Environment (ed. AE Hall), 83-87. CRC Press, Boca Raton, FL, USA.

Hall AJ, Chimenti CA, Vilella F, \& Freier G (1985) Timing of water stress effects on yield components in sunflower. In: Proceedings of XI International Sunflower Conference Mar del Plata, Argentina, 131-136. International Sunflower Association, Paris, France.

Hall AJ, Connor DJ, \& Whitfield DM (1990) Root respiration during grain filling in sunflower, the effects of water stress. Plant and Soil 121, 57-66.

Hutchison CM \& McGiffen ME (2000) Cowpea cover crop mulch for weed control in desert pepper production. HortScience 35, 196-198.

Janssen PHM \& Heuberger PSC (1995) Calibration of processoriented models. Ecological Modeling 83, 55-66.

Kropff MJ \& Van Laar HH (1993) Modeling Crop-Weed Interactions. CAB International and the International Rice Research Institute, Wallingford, UK.

Lemerle D, Verbeek B, \& Coombes NE (1996) Interaction between wheat (Triticum aestivum) and diclofop to reduce the cost of annual ryegrass (Lolium rigidum) control. Weed Science 44, 634-639.

Lindquist JL (1997) An Ecophysiological Approach to Understanding Corn Tolerance and Velvetleaf Suppressive Ability. PhD thesis, University of Nebraska-Lincoln, Lincoln, Nebraska, USA.

Lindquist JL (2001) Performance of INTERCOM for predicting Zea mays-Abutilon theophrasti interference across north-central United States. Weed Science 49, 195-201.

Lindquist JL \& Kropff MJ (1996) Improving rice tolerance to barnyardgrass through early crop vigor, simulations with INTERCOM. In: System Approaches for Sustainable Agricultural Development, Applications of Systems Approaches at the Field Level (eds. MJ Kropff, PS Teng, PK Aggarwal, J Bouma, BAM Bouman, JW Jones, \& HH Van Larr), 53-62. Kluwer Academic Publishers, Dordrecht, the Netherlands.

Lindquist JL \& Mortensen DA (1998) Tolerance and velvetleaf (Abutilon theophrasti) suppressive ability of two old and two modern corn (Zea mays) hybrids. Weed Science 46, 569-574.

Lindquist JL \& Mortensen DA (1999) Ecophysiological characteristics of four maize hybrids and Abutilon theophrasti. Weed Research 39, 271-285.

Mayberry KM, Natwick EN, Gonzalez RA, Holmes GH, Bell CE, \& Bali KM (1995) Guidelines to Production Costs and Practices. Circular 104-V, University of California Cooperative Extension, California, USA.

Nangju D (1978) Effect of plant density, spatial arrangement, and plant type on weed control in cowpea and soybean. In: Weeds. and Their Control in the Humid and Subhumid Tropics (ed. IO Akobundu), 288-299. International Institute for Tropical Agriculture, Ibadan, Nigeria.

Paolini R, Faustini F, Saccardo F, \& Crino P (2006) Competitive interactions between chick-pea genotypes and weeds. Weed Research 46, 335-344.

Penning de Vries FWT, Jansen DM, Tenberge HFM, \& Bakema A (1989) Simulation of Ecophysiological Processes of Growth in Several Annual Crops. Pudoc, Wageningen, the Netherlands. 
Robinson RG (1971) Sunflower phenology - Year, variety, and date of planting effects on day and growing degree-day summations. Crop Science 11, 635-638.

Schneiter AA (1997) Sunflower Technology and Production. American Society of Agronomy, Madison, WI, USA.

Spitters CJT, Van Keulen H, \& Van Kraalingen DWG (1989) A simple and universal crop growth simulator, SUCROS87. In: Simulation and Systems Management in Crop Protection (eds. R Rabbinge, SA Ward, \& HH Van Laar), 147-216. Pudoc, Wageningen, the Netherlands.

Steinmaus SJ, Prather TS, \& Holt JS (2000) Estimation of base temperatures for nine weed species. Journal of Experimental Botany 51, 275-286.

Wang G (2005) Competitiveness of Erect, Semi-erect, and Prostrate Cowpea (Vigna unguiculata) Genotypes with Sunflower (Helianthus annuus) and Purslane (Portulaca oleracea): Experiments and Simulations. PhD thesis, University of California, Riverside, CA, USA.
Wang G, Ehlers JD, Ogbuchiekwe EJ, Yang S, \& McGiffen ME, Jr. (2004) Competitiveness of erect, semi-erect, and prostrate cowpea (Vigna unguiculata) genotypes with sunflower (Helianthus annuus) and purslane (Portulaca oleracea). Weed Science 52, 815-820.

Wang G, Ehlers JD, Marchi ECS, \& McGiffen ME, Jr. (2006a) Competitive ability of cowpea (Vigna unguiculata) genotypes with different growth habit. Weed Science 54, 775-782.

Wang G, McGiffen ME, Jr., \& Ehlers JD (2006b) Replacement series of six cowpea (Vigna unguiculata) genotypes with sunflower (Helianthus annuus) or purslane (Portulaca oleracea). Weed Science 54, 954-960.

Zalom FG, Goodell PB, Wilson LT, Barnett WW, \& Bentley WJ (1983) Degree-Days, the Calculation and Use of Heat Units in Pest Management: University of California Division of Agriculture and Natural Resources Leaflet 21373. University of California, Berkeley, CA, USA. 